BULLETIN Bulletin hispanique

HISPANIQUE Université Michel de Montaigne Bordeaux

118-1 | 2016

La Guerre Civile espagnole aujourd'hui (1936-2016)

\title{
Les intellectuels espagnols face à la Guerre Civile (1936-1939)
}

\section{Paul Aubert}

\section{(2) OpenEdition}

\section{Journals}

\section{Édition électronique}

URL : http://journals.openedition.org/bulletinhispanique/4257

DOI : 10.4000/bulletinhispanique.4257

ISSN : 1775-3821

\section{Éditeur}

Presses universitaires de Bordeaux

\section{Édition imprimée}

Date de publication : 15 juillet 2016

Pagination : 119-136

ISBN : 979-10-300-0058-0

ISSN : 0007-4640

\section{Référence électronique}

Paul Aubert, "Les intellectuels espagnols face à la Guerre Civile (1936-1939) », Bulletin hispanique [En ligne], 118-1 | 2016, mis en ligne le 15 juillet 2019, consulté le 07 septembre 2019. URL : http:// journals.openedition.org/bulletinhispanique/4257 ; DOI : 10.4000/bulletinhispanique.4257 


\title{
Les intellectuels espagnols face à la Guerre Civile (1936-1939)
}

\author{
Paul Aubert \\ Aix-Marseille Université. CNRS-UMR
}

La guerre civile de 1936 signifie en Espagne la fin de l'intellectuel traditionnel qui signe des manifestes, prononce des discours et rédige des articles de presse. Ses voies d'action et ses moyens d'expression sont devenus inutiles. Il est tenu pour responsable de l'échec de la République et accusé de tous les maux. Après avoir été tout, l'intellectuel n'était plus rien, constatait Ortega. Certains avaient pris le chemin de l'exil dès 1936. D'autres étaient devenus des militants.

Mots-clés : intellectuels, II ${ }^{e}$ République, Guerre civile, Espagne.

La Guerra Civil significa en España el fin del intelectual tradicional que firma manifiestos, pronuncia discursos y redacta artículos de prensa. Sus vías de acción y sus medios de expresión han llegado a ser inútiles. Es considerado responsable del fracaso de la República y culpable de todos los males. El intelectual que lo era todo, ha llegado a no ser nada, comprueba Ortega. Algunos salieron para el exilio desde el verano de 1936. Otros se habían transformado en militantes.

Palabras clave: intelectuales, II República, Guerra Civil, España.

The 1936 Spanish Civil War means in Spain the end of the traditional intellectual, signing manifestos, makes speeches and writes articles for the newspapers. His means of action and expression have become useless. He is hold responsible for the failure or the Republic, accused of all evils. After having been everything, the intellectual was nothing, Ortega notices. Some had taken the route of exile, others had become militants.

Keywords: intellectuals, II ${ }^{\text {th }}$ Republic, Civil War, Spain. 
T a guerre civile de 1936 signifie en Espagne la fin de l'intellectuel traditionnel qui signe des manifestes, prononce des discours et rédige des articles de presse. Ses voies d'action et ses moyens d'expression sont devenus inutiles : les partis politiques sont sans voix, la presse est censurée. L'intellectuel devient alors un militant ou disparait, son discours n'est plus audible. S'il prend parti, c'est pour un camp dont il évalue le programme politique en cas de victoire immédiate. De surcroît, l'histoire s'est accélérée. De ce point de vue, la Guerre civile marque une césure, même si la figure publique de l'intellectuel est mise à profit par la droite pour envisager une revanche sur le libéralisme. Comme jadis Maurras, au début des années dix, les intellectuels phalangistes ont compris l'intérêt qu'il y avait, au lieu de le dénigrer, à se substituer à l'intellectuel libéral pour, comme lui, faire appel à l'opinion. Les écrivains partisans du régime de Burgos se dotèrent de nouveaux organes. Les poètes forgèrent un style qui contrastait avec l'académisme des écrivains phalangistes madrilènes et ne plaisait pas aux lecteurs traditionnalistes. « Reçois ma prière de poudre et d'Ave maria " ("Recibe mi oración de pólvora y avemarías"), écrivait un blessé (" caído »), Rafael García Serrano, dans un poème intitulé "Exaltaciones ». F. Yzurdiaga, fondateur de Arriba España de Pampelune, leur répondit en assignant un nouveau rôle à l'intellectuel : "Peu nous importe que les petites gens ne nous comprennent pas. Il suffit que nous comprenne et approuve la fraternité des intellectuels d'Espagne et hors d'Espagne, les gens qui ont une conception impériale et exaltée de l'existence. $»^{1}$.

Après trois générations d'intellectuels qui se sont succédé depuis le milieu du XIX $^{e}$ siècle afin de protester contre l'État au nom de la raison ou de la justice, faire de la politique, puis préparer la révolution, l'intellectuel de gauche, frustré par l'échec de la République (qu'il avait assimilé à la démocratie ou pris pour une étape vers un régime révolutionnaire), face au virage autoritaire qu'il pressent, sait qu'il sera combattu sur son propre terrain et qu'il devra choisir son camp et ne plus se contenter de revendiquer l'historicisme ou de décrire un monde cartésien².

\section{LA FIN DE LA POLITIQUE : VERS L'AFFRONTEMENT}

L'intellectuel libéral, formé à l'étranger, pensait avoir atteint son but en contribuant à l'avènement de la Seconde République, mais quelques mois après il entra en dissidence. Unamuno et Ortega dirent « non » au nouveau régime,

1. Jerarquia, n 16, XII.1936 et Arriba España, Pampelune, 1.VIII.1937.

2. Paul Aubert, "Les intellectuels espagnols et l'avènement de la Deuxième République (1930-1931) ", Angelo Colombo (éd.), Recherches en littérature et civilisation européennes et hispano-américaines, Besançon, PUFC, 2009, p. 115-124 ; "Vieille et nouvelle politique" : l'impossible relève générationnelle, 1868-1936 ", P. Aubert (coord.), Transitions politiques et culturelles (XIX'-XX ${ }^{e}$ siècle) Mélanges de la Casa de Velázquez, Madrid, n 36-1, 2006, p. 49-82; Les intellectuels espagnols et la politique dans le premier tiers du XX' siècle, thèse d'État-ès-lettres, Univ. Bordeaux III, J. Pérez dir., Lille, ANRT, 1996, 1886 p. 
qu'ils trouvaient dogmatique ${ }^{3}$, tandis qu'Araquistáin finit par préparer la révolution dont la république réformatrice qu'il avait soutenue dans les mêmes termes qu'Azaña - c'était une révolution "blanche », par la loi, afin d'éviter une révolution " rouge ", sanglante - n'aurait été à son avis qu'une étape ou une utopie. Celle-ci consistait, selon lui, à avoir cru qu'il était possible de réaliser une révolution sociale au moyen d'une Constitution républicaine. «En réalité, tout ce que les partis républicains peuvent offrir et les partis ouvriers admettre - s'ils en avaient envie - tient sur une feuille de papier à cigarettes ", ironisaitil encore en 1935. Déjà l'année précédente, il formulait un dilemme : "On renonce à la révolution ou on renonce à la loi » ${ }^{4}$. Il croyait tirer la leçon de la répression des luttes sociales européennes dont il avait été le témoin depuis son ambassade à Berlin, où il avait vu Hitler porté au Pouvoir par le suffrage universel, et proclamait la légitimité d'une révolution violente face à une démocratie fictive et de surcroît menacée.

\section{Polarisation idéologique après l'insurrection d'octobre 1934}

Quelques mois auparavant, après l'échec de l'épisode asturien qui divisa les intellectuels au sein du PSOE, la gauche voulut voir dans la victoire du Front Populaire une condamnation de la répression de l'insurrection. La droite interprétera le soulèvement du 18 juillet 1936 comme une réponse à celle-ci, en suggérant, comme Salvador de Madariaga, qu’avec «la rébellion de 1934, la gauche espagnole [avait] perdu jusqu'à l'ombre de son autorité pour condamner la rébellion de 1936 ". Mais les intellectuels, qui se rassemblèrent pour dénoncer dans un manifeste célèbre la répression du mouvement d'octobre, ne prétendaient pas aller au-delà. Chaque camp affirmait qu'il se disposait à briser les urnes et semblait convaincu qu'une nouvelle étape se préparait au sein d'une République désormais sans républicains. Largo Caballero avait affirmé que si la droite venait à gagner, "il déclencherait immédiatement la guerre civile ». Gil Robles évoquait également cette éventualité que, depuis la répression des manifestations de 1917, Zulueta, Domingo et même, à sa façon, Unamuno, ne manquaient pas d'évoquers.

3. P. Aubert, «Los intelectuales en el Poder (1931-1933): del constitucionalismo a la Constitución», Manuel Tunón de Lara, José-Luis García Delgado (eds.), La II República. El primer bienio, Madrid, Siglo XXI, 1987, p. 169-231; «Intelectuales y cambio político», M. Tuñón de Lara (dir.), Los orígenes culturales de la II República, Madrid, Siglo XXI, 1993, p. 25-99.; «Los intelectuales y la II República», Ayer, n 40, Madrid, Marcial Pons, 2001, p. 105-133; La Frustration de l'intellectuel libéral (Espagne 1808-1939), Cabris, Sulliver, 2010, 380 p.

4. Luis Araquistáin, «Las dos constituciones. Con la ley o por encima de la ley», El Liberal, 14.VI.1917; «Revisión de conceptos. La revolución blanca», El Liberal, 21.VI.1917; «Revisión de conceptos. Revolución y reforma», El Liberal, 26.VI.1917; «La utopía de Azaña», Leviatán, $n^{\circ}$ 5, IX. 1934, p. 18-30; «El mito Azańa», Ibid., n 18, X-XI 1935, p. 6; pról. a Francisco Largo Caballero, Discurso a los trabajadores, Madrid, Gráfica socialista, 1934, p. XIII; P. Aubert, "Manuel Azaña : un intellectuel au Pouvoir», J. P. Amalric-P. Aubert (éds.), Manuel Azaña et son temps, Madrid, CNRS-Casa de Velázquez-Ville de Montauban, 1993, p. 305-327.

5. L. Araquistáin, «Vida nacional. La guerra civil», España, n² 22, 25.VI.915, p. 8-9; P. Aubert, 
L'échec de la droite fit perdre des militants à la CEDA et en fit gagner à la Phalange Espagnole, groupe fascisant créé en 1934. José Antonio Primo de Rivera, son leader, le fils de l'ancien dictateur, prévenait qu'il ne respecterait pas un résultat électoral " qui serait contraire au destin éternel de l'Espagne ". Quant à José Calvo Sotelo, le dernier ministre des Finances de Primo de Rivera, il expliquait que "Le fascisme [...] n' [était] pas une action, mais une réaction " au communisme ${ }^{6}$. Madariaga faisait le même constat : "Partout et en tous temps, les dictatures se sont produites en haut quand régna l'anarchie en bas [...] chaque fois que pourrit un état social, de ses entrailles surgit une dictature de fer. Le fascisme c'est, dans le cas de l'Espagne et de la France, l'ombre fatale que projette sur le sol du pays la démocratie elle-même, lorsque sa décomposition interne la transforme en anarchie. » ${ }^{7}$. Tandis que le Gouvernement appliquait son programme, se multipliaient les rumeurs de conspiration militaire et se succédaient les incendies d'églises et de couvents ainsi que les agressions et les attentats perpétrés par l'extrême gauche ou l'extrême droite. À la fin du mois de mai, on arrêta 28 membres de la Phalange Espagnole et l'on ordonna la fermeture des syndicats de la CNT. Le 28 mai, José A. Primo de Rivera insultait le tribunal qui venait de le condamner à un an de prison pour détention d'armes. La confusion fut encore plus grande quand, lors d'une manifestation socialiste des leaders du parti, Indalecio Prieto et le Dr. Negrín, furent agressés par des partisans de Largo Caballero, à Écija, le 31 mai 1936. Au cours du meeting de Saragosse, ce furent los anarco-sindicalistes (pour qui l'URSS était aussi mauvaise que l'Allemagne) qui menaçèrent les socialistes. Au début du mois de juin, les adhérents de l'UGT et de la CNT voulurent déclencher une grève contre leurs dirigeants. Celle-ci expliqua que, puisqu'elle ne faisait pas partie du Front Populaire, rien ne l'obligeait à collaborer avec le Gouvernement. Gregorio Marañón prévoyait, le 2 juin dans El Sol, qu’après la chute du Gouvernement, le pays, bipolarisé, devrait affronter d'une part la réaction et d'autre part le marxisme.

Au cours de la session des Cortès du 16 juin 1936, Gil Robles expliqua que le pays n'était plus gouverné et vivait en pleine anarchie. Et Joaquín Maurín, le leader du parti trotskiste, le POUM, déclara qu'il existait une situation préfasciste. Dès lors, la presse fit état de rumeurs qui annonçaient l'imminence d'un coup d'État auxquelles Azaña ne prêta guère attention. Mola poursuivait la rédaction de ses « instructions réservées " pour dessiner un futur pouvoir disposé à gouverner par Décrets-lois approuvés postérieurement par une assemblée constituante. Celle du 5 juin prévoyait pêle-mêle la suspension de la Constitution de 1931, la dissolution des Cortès et l'extinction de l'analphabétisme. Elle se terminait par une profession de foi qui serait ensuite

"La "Guerra civil" de Miguel de Unamuno», Circunstancia, n 19, V. 2009, Revista de Ciencias Sociales, Instituto Universitario Ortega y Gasset, Revista Electrónica Cuatrimestral, Madrid.

6. Diario de las Cortes, 17.IV.1936. Cette même année Madariaga publie, Anarquía o jerarquía,

7. S. de Madariaga, España, Buenos Aires, ed. Sudamericana, 1944, p. 550. Sauf indication contraire, c'est nous qui traduisons. 
supprimée : "Le directoire s'engagera pendant sa conduite des affaires à ne pas changer le régime républicain [...] et à adopter toutes les mesures qui lui sembleront nécessaires à la création d'un État fort et discipliné " ". "Il n’y a plus de solutions pacifiques", expliquait la feuille phalangiste No importa?. Le Gouvernement devait combattre les militaires de droite et les membres de la Phalange, ainsi que les anarco-sindicalistes, mais il dépendait des ouvriers et des casernes. Le 12 juillet, des phalangistes assassinèrent à Madrid un militant socialiste, le lieutenant Castillo. Le lendemain, eut lieu l'exécution du député monarchiste, ancien ministre des Finances de la Dictature de Primo de Rivera, José Calvo Sotelo. On considère ces deux crimes comme le début de la Guerre civile. Cependant, le soulèvement avait été préparé minutieusement : dans chaque ville un officier s'efforça de déclarer l'état de guerre.

\section{La fragilité de la République}

Les institutions de la République continuèrent à fonctionner sur le territoire qu'elle put défendre. Ce n'était plus le régime que les intellectuels avaient imaginé. Ceux-ci semblaient être victimes d'un malentendu. Ils avaient mal évalué le poids des tâches de gouvernement et la situation de celui-ci au sein du nouvel équilibre des forces politiques et sociales. Le 16 avril 1936, Azaña leur avait répondu qu'il avait fait ce qu'il avait pu, et présentait comme une évidence le fait que tous les députés pussent respecter la Constitution, en attendant qu'éventuellement les Cortès la réformassent, comme le proposaient José Ma Gil Robles et Miguel Maura. À la fin de 1935, José Castillejo commentait également cette possibilité dans $\mathrm{El} \mathrm{Sol}^{10}$. La question fit l'objet d'un débat, annoncé sous le titre: "Tres años de experiencia constitucional", après les conférences prononcées par le président de la République. Castillejo consacra un long article au "nouveau libéralisme " au cours de la campagne électorale de février 1936 tandis que les juristes ne cessèrent de gloser les arguments défendus respectivement par Alcalá Zamora et par le Ministre de l'Instruction Publique Joaquín Dualde. Le caractère sacré du texte adopté le 9 décembre 1931 irritait certains intellectuels. La mystique de la République qu'ils avaient contribué à créer débouchait sur une tautologie, voire une téléologie, qui ne toléraient pas la critique. La République semblait donc être victime d'elle-même. Castillejo fit l'inventaire de ce qui pourrait changer dans l'attitude des gouvernants en commençant par une nouvelle définition des tâches de l'État. Ces limites légales semblaient insupportables à certains, mais Azaña se plaisait à les évoquer comme une étape nécessaire, lorsqu’on l'accusait d'instaurer un régime communiste avec le Front Populaire et que l'on rappelait les malentendus de 1931. Le pays était scindé en deux, entre

8. Joaquín Arrarás, Historia de la II República Española, t. IV, Madrid, ed.Nacional, 1968, Madrid, p. 308.

9. Federico Bravo Morata, Historia de la República, t. II, Madrid, Daimon, 1977, p. 288.

10. J. Castillejo, «La reforma constitucional. ¿`Tenemos Constitución?», El Sol, 10 .XII.1935. 
ceux qui redoutaient la révolution et ceux qui s'opposaient au fascisme. La gauche était fractionnée et en son sein les socialistes étaient divisés tandis que les communistes s'efforçaient de s'introduire dans les organisations socialistes. Si en 1917 les intellectuels les plus radicaux du PSOE étaient convaincus de faire la Révolution française de 1789, ou tout au plus la russse de 1905 ; si, en 1926, les signataires du manifeste d'Alianza Republicana se référaient au passé ("Venimos en el siglo XX a luchar por la libertad conquistada en el siglo XIX»); à la fin de 1933, la gauche radicalisée du PSOE se préparait à une conquête violente du Pouvoir. Araquistáin l'annonçait dans sa préface aux Discursos a los trabajadores de Largo Caballero : "Nos illusions du 14 avril se sont évanouies, de telle sorte que le dilemme n'est plus Monarchie ou République; République ou Monarchie, il n'y a qu'un seul dilemme, hier comme aujourd'hui, aujourd'hui comme demain: dictature capitaliste ou dictature socialiste ". C'est ainsi que le dilemme entre la réforme et la révolution, selon le modèle de Joquín Costa, s'était teinté de nuances bolcheviques au point de se transformer en raison dialéctique : révolution ou contre-révolution.

Le contexte international n'était pas favorable à la consolidation d'une démocratie en Espagne. Les intellectuels au Pouvoir, et, le premier d'entre eux, Manuel Azaña, n’avaient pas évalué les rapports de forces et le poids des résistances, ou n'avait plus la force de les esquiver. Un secteur de la société, appuyé sur l'armée, prétendra à nouveau avoir le monopole du sentiment national, les autres essaieront de défendre l'état de droit ou de faire une autre révolution. De part et d'autre, le cercle vicieux de la violence prit le pas sur la raison. Ortega, après Baroja, Araquistáin, Besteiro, comme Lénine, se plaisait à dire que le recours aux sages de la tribu n'était que la preuve d'un déficit démocratique et que le rôle des intellectuels était de faire en sorte que, lorsqu'ils auraient éduqué le peuple, on n'eût plus besoin d'eux ${ }^{11}$.

\section{ChOISIR SON CAMP : UNE BATAILlE DE MANIFESTES}

Comme lors de la Première Guerre mondiale, on brandit à usage interne des arguments tirés de l'actualité internationale. Désormais les intellectuels espagnols signaient à nouveau des manifestes et se joignaient à l'action des comités antifascistes européens. Araquistáin présenta le soulèvement d'octobre 1934 comme "une défense violente de la légitimité républicaine et démocratique ». En Espagne, outre cet auteur qui consacra le tiers de ses articles de la revue Leviatán, qu'il venait de fonder, à dénoncer le danger fasciste, c'est la presse communiste qui accordait la plus grande importance

11. "L'idéal d'un peuple est de ne pas se voir obligé à ce qu'interviennent dans sa politique les intellectuels, car cela veut dire que chez ce peuple les choses ne vont pas bien. ", redit Ortega devant les Cortès Constituantes, le 4 septembre 1931 (Diario de Sesiones, n 33, 4.IX.1931, p. 777). "Le rôle des intellectuels consiste à rendre inutile l'existence de dirigeants spécialisés, intellectuels. " (Ce que sont les " amis du peuple " et comment ils luttent contre les socialdémocrates, Lénine, 1894, Euvres, Moscou, t. 1, p. 321). 
à ce phénomène. Le débat social s'était radicalisé, la presse avait remplacé le commentaire de l'actualité internationale par un discours idéologique. Sur les quarante-cinq conférences prononcées à l'Athénée de Madrid entre les mois de décembre 1933 et septembre 1934, quatorze furent consacrées à la question de l'engagement des intellectuels, à l'URSS et au fascisme. Le virage socialiste de 1934 a éloigné les intellectuels de la gauche, même si quelques-uns d'entre eux se rassemblèrent pour dénoncer la répression de l'insurrection asturienne d'octobre 1934 en adhérant au « Manifeste pour protester contre la sentence infligée aux assassins du journaliste Luis de Sirval ». Cette guerre de manifestes se poursuivit jusqu'en $1939^{12}$. Antonio Machado, qui avait été nommé, en 1936, président de la Casa de la Cultura, parla en public, et à la radio, signa de nombreux manifestes et participa, en juillet 1937, au II ${ }^{e}$ Congrès des Intellectuels Antifascistes pour la Défense de la Culture. Il avait rencontré quelques écrivains russes, notamment Ilya Erenbourg avec Rafael Alberti au café Varela. Le poète n'admettait pas la propagande du soi-disant camp national qui affirmait que les intellectuels demeurés aux côtés de la République servaient une cause étrangère ${ }^{13}$. Que les congrès des intellectuels antifascistes aient été parfois le fruit d'une tentative de captation des intellectuels occidentaux par le Komintern ne présuppose pas la cécité absolue des écrivains qui militèrent en son sein ${ }^{14}$. On accusa les intellectuels de tous les maux puisqu'ils osèrent un jour prétendre que la République était à eux et qu'ensuite, après avoir voulu la monopoliser, ils la renièrent ${ }^{15}$.

12. Le 11 juin 1933, Unamuno, Jiménez de Asúa, Marañón et le juriste Recasens Siches appellent à la formation d'un "Comité d'intellectuels conscients pour aider les victimes de la terreur nazie ». Le 14 juillet, à l'occasion de la visite d'Henri Barbusse à l'Athénée de Madrid, est créé le Comité d'Aide Antifasciste présidé par Jiménez de Asúa. Depuis le mois d'avril 1934, l'actualité internationale réunit à nouveau leurs signatures au pied de manifestes contre le nazisme, l'intervention italienne en Abyssinie en 1935, le régime d'Oliveira Salazar au Portugal en 1936. Marañón signa également le manifeste de l'Association des Amis de la Russie et celui des Ennemis d'Hitler; Antonio Machado, les manifestes de solidarité avec les peuples opprimés. Il est également le premier signataire, en avril 1934, du Manifeste contre la terreur nazie, avec Sender, Alberti et $\mathrm{M}^{\mathrm{a}}$ Teresa León, notamment (Heraldo de Madrid, 7.IV.1934). Il approuve aussi le Manifeste contre l'agression de l'Italie en Abyssinie, le 6 novembre 1935, les deux manifestes du «Comité des amis du Portugal » qui dénoncent, le 6 mai et le 4 juillet 1936 « les méthodes brutales de répression de la dictature fasciste de Salazar " (La Vanguardia, 22.IV.1938.) et, le Manifeste de solidarité avec le peuple chinois, en avril 1938. Tout au long de cette période, Machado, plus sollicité que jamais, signe de nombreux manifestes, au point d'apparaittre -peutêtre avec Menéndez Pidal- comme le seul intellectuel de sa génération présent dans presque toutes les manifestations. Il adhère, le 8 août 1936, avec Menéndez Pidal, Marañón, Pérez de Ayala, Pittaluga, Marichalar et Ortega y Gasset, entre autres, à celui des intellectuels qui expriment leur soutien au Gouvernement (Ahora, 31.VII. et 1.XI.1936) ainsi qu'au Manifeste de l'Alliance des Intellectuels Antifascistes (El Mono Azul, 19.XI.1936) et à celui qui annonce la première évacuation des intellectuels de Madrid, le 29 novembre 1936.

13. Prosas Completas (PC), Madrid, Espasa, 1988, t. II, p. 2519 et 2521.

14. Stephen Koch, La fin de l'innocence. Les intellectuels d'Occident et la tentation stalinienne. 30 ans de guerre secrète, Paris, Grasset, 1995, 483 p.

15. Azorín, «Estafeta de alcance. La República es de los intelectuales», Crisol, 4.VI.1931. 
Le 18 octobre 1936, Juan de Castilla, dans l'édition de Séville du quotidien $A B C$, attaquait les intellectuels restés fidèles à la République. Dans un article intitulé " Des intellectuels incontrôlés », ("Intelectuales desmandados»), il citait un manifeste républicain reproduit par la presse étrangère. Quelques mois plus tard, quelques signataires et, en particulier, d'anciens membres du parti d’Ortega (la Agrupación al Servicio de la República) s'éloignèrent du régime qu'ils avaient contribué à créer. Triste épilogue : de nombreux intellectuels s'en vont, élégamment ou non, à partir de l'été 36. D'autres continuèrent à signer des manifestes en faveur de la République, mais leur itinéraire est loin d'être rectiligne.

\section{Clivages et confusions}

Le soulèvement militaire du 18 juillet eut des connotations anti-intellectualistes et fut suivi de l'exécution arbitraire de personnalités du monde de la culture ou de la politique : Federico García Lorca, à Grenade; Leopoldo Alas Argüelles, le fils de Clarín, à Oviedo ; Manuel Ciges Aparicio, Gouverneur civil d'Ấvila, beau-frère d'Azorín, par exemple ${ }^{16}$. Après l'assassinat de Calvo Sotelo, Ortega comprit que, dans les deux camps, le cercle vicieux des représailles ne pourrait être brisé. Ramiro de Maeztu, qui était, depuis la publication de son livre Defensa de la Hispanidad, en 1934, l'un des plus importants idéologues de droite, fut arrêté à Madrid, le 31 juillet 1936 et fusillé, le 28 octobre. Selon ses amis, il était en proie à un délire paranoïaque depuis l'avènement de la République. Malade, Ortega abandonna sa villa du lotissement «El Viso » qui fut l'une des premières fouillées ${ }^{17}$. Bien qu'il ait refusé de signer le manifeste des intellectuels antifascistes parce qu'il ne voulait critiquer nommément personne ${ }^{18}$, on trouve son nom au pied d'un communiqué publié, le 31 juillet $1936^{19}$, par $A B C$, devenu un "quotidien de gauche " contrôlé par la UGT. Si la sincérité de telles adhésions est mise en doute par la presse " nationale », elle l'est également

16. José Luis Rodríguez Jiménez, «Ni División Azul, ni División Española de Voluntarios: El personal forzado en el cuerpo expedicionario enviado por Franco a la URSS", Cuadernos de Historia Contemporánea, Univ. Complutense, Madrid, 2009, vol. 31, p. 265-296.

17. Eugenio Vegas Latapié, Escritos politicos, Madrid, 1940, p. 241-242 et p. 250; Los caminos del desengaño. Memorias políticas, t. II (1936-1938), Madrid, Tebas, 1987, p. 268.

18. Miguel Ortega, Ortega y Gasset, mi padre, Barcelone, 1983, p. 130-132.

19. "Adhésion d'intellectuels. Les soussignés déclarons que, face à l'affrontement qui a lieu en Espagne, nous sommes aux côtés du Gouvernement de la République et du peuple, qui avec un héroïsme exemplaire lutte pour ses libertés. " Les autres signataires étaient Ramón Menéndez Pidal (président de l'Académie Espagnole), Antonio Machado (poète), Gregorio Marańón (médecin et académicien), Teófilo Hernando (médecin et professeur d'université), Ramón Pérez de Ayala (ancien ambassadeur), Juan Ramón Jiménez, Gustavo Pittaluga (médecin et professeur d'université), Juan de la Encina, directeur du Musée d'Art Moderne, Gonzalo Rodríguez Lafora (médecin et professeur d'université), Pío del Río Hortega (médecin et professeur d'université), Antonio Marichalar (écrivain) y José Ortega y Gasset (philosophe). (ABC, Séville 13.X.1936). 
par certains organes socialistes, comme Claridad, proches de Largo Caballero ${ }^{20}$. L'année suivante, furent connues les explications de certains de ces intellectuels libéraux. Marańón, dont le fils - comme celui de Pérez de Ayala - combattit dans les rangs des soi-disant "nationaux " sur le front de Madrid finit par craindre pour sa vie. Après sa comparution devant une checa y un tribunal populaire et avoir constaté que l'on venait d'interdire la réédition de l'un de ses livres, il s'embarqua, avec sa famille, en décembre 1936, à Alicante sur le destroyer anglais Active, avec pour sauf-conduit une carte de la CNT ${ }^{21}$. Le médecin, qui n'occupait plus son siège de député depuis la dissolution de son parti en 1933 (La Agrupación al Servicio de la República), mais avait pris la parole plusieurs fois sur les ondes de radios procommunistes, précisa, le 20 mars 1937, depuis Santiago du Chili, qu'il signa ces manifestes sous la menace ${ }^{22}$. Ortega sera tout aussi explicite dans "l'épilogue pour les Anglais", ajouté en 1937, à la nouvelle édition de La révolte des masses ${ }^{23}$. Avant d'aller à Valence, Antonio Machado adhéra, en décembre 1936, à une déclaration collective de remerciement à l'égard du comandante Carlos, Vittorio Vidali, qui dirigea le Quinto Regimiento (chargé de développer l'éducation et la culture et auquel appartinrent de nombreux écrivains) qui fusionna ensuite avec l'Armée populaire ${ }^{24}$.

\section{Antintellectualisme. Épuration}

L'esprit vindicatif et l'intransigeance qui avaient caractérisés jadis l'Espagne réactionnaire, viennent justifier de nouveau l'épuration entreprise par le nouveau régime. Était considéré suspect quiconque n'appartenait pas à une famille de droite depuis plusieurs générations. Cette version franquiste de la pureté de sang allait jusqu’à contester le comportement et la couleur idéologique des individus : celui qui, au cours d'une réunion, semblait trop prudent était soupçonné d'être un " rouge ». Dans le soi-disant camp " national ", cette conjoncture alimente le mépris des conservateurs à l'endroit des intellectuels. Le pédiatre Enrique Suñer y contribua au sein de la Commission d'épuration, créée le 7 décembre 1936. Juan Tusquets avait déjà donné le signal de la lutte antisémite et antimaçonnique en 1932 dans un livre intitulé Origenes de la Revolución española ${ }^{25}$. Enfin, Fernando Martín Sánchez Juliá tenait pour

20. Cité par Manuel Rubio Cabeza, Los intelectuales..., op. cit., p. 198-199.

21. G. Marañón, «Las pedanterías del crimen », El Pueblo, Montevideo, 6.III.1937. María Zambrano, "Carta al Doctor Marañón", Los intelectuales en el drama de España, op. cit., p. 57. «Dos direcciones opuestas separan a los intelectuales españoles. Y cuando alguien de quien esperamos otra cosa, toma la que no es ni puede ser nunca la nuestra, venza quien venza, querríamos en ese instante inmediato anterior a la marcha aún unas palabras» (p. 58).

22. Lettre à José Pijoan, citée par Marino Gómez Santos, Españoles sin frontera, Madrid, Planeta, 1983.

23. O.C., t. 4, op. cit., p. 306.

24. Milicia Popular, $\mathrm{n}^{\circ} 116,1^{\text {er }}$ décembre 1936.

25. E. Suñer, Los intelectuales y la tragedia española, op. cit.; Juan Tusquets, Orígenes de la 
responsable de la décadence de l'Espagne les krausistes et Giner de los Ríos dans un ouvrage anonyme intitulé Una poderosa fuerza secreta. La Institución Libre de Enseñanza ${ }^{26}$.

Une nouvelle inquisition fonctionna destinée à lutter contre l'ennemi intérieur et à revenir à un ordre antérieur au lieu d'en instaurer un nouveau, même si dans la mythologie franquiste on présentait le soulèvement du 18 juillet comme le début d'une ère nouvelle. Après avoir discrédité - ou exécuté - les intellectuels qui un jour approuvèrent l'avènement de la République, ceux qui prétendaient agir dans l'urgence au nom de la nation, les soi-disant "nationaux ", prétendirent monopoliser la patrie, en préséntant la Guerre civile comme : "le couronnement d'un processus historique, [...] la lutte de la Patrie contre l'anti-patrie, de l'unité contre la sécession, de la morale contre le crime, de l'esprit contre le matérialisme ${ }^{27}$. Cette conception de l'histoire nationale justifia le fait que l'on cherchât à imposer l'idée d'une croisade contre le paganisme. Selon de tels critères, les «nationaux " étaient les vrais Espagnols et les autres, des « rouges » dont l'épuration devait prolonger la victoire des premiers. Une série de décrets expulsa, en juillet et août 1939, des professeurs d'universitée ${ }^{2}$. On commença aussi à poursuivre les fonctionnaires restés fidèles à la légalité républicaine et à éliminer tous les vestiges du régime précédent, avec un zèle qui dépassait l'imagination, car les morts ne furent pas épargnés. C'est ainsi qu'Antonio Machado fit l'objet, jusqu'en décembre 1957, d'une enquête destinée à démontrer son appartenance à la franc-maçonnerie ${ }^{29}$. On dénonçait encore comme en 1931 - lorsque José Antonio désignait à Ortega $^{30}$ - les pseudo-intellectuels antipatriotes, des dissidents hétérodoxes qu'il fallait maintenir éloignés de la vie nationale. Le général Franco fut fidèle à la profession de foi anti-intellectualiste, qu'il avait faite dans son roman autobiographique, Raza, publiée sous le pseudonyme de Jaime de Andrade, et, comme la plupart des jeunes officiers qui avaient crié « Mort aux intellectuels » à la sortie de l'institution de la calle del Prado, demeura hostile à l'Athénée, symbole de la conscience démocratique. Cette méfiance explique sans doute, malgré les efforts de Dionisio Ridruejo ou de Giménez Caballero, l'absence d'intellectuel organique du franquisme, au contraire de l'Italie de Mussolini

Revolución española, Barcelone, Editorial Vilamala, 1932, 215 p.

26. Una poderosa fuerza secreta. La Institución Libre de Enseñanza, S. Sebastián, Ed. española, $1940,280 \mathrm{p}$.

27. Francisco Franco, «Declaraciones al representante de la Agencia Havas, el 27 de agosto de 1938", Palabras del Caudillo, Madrid, Ed. Nacional, 1943, p. 532.

28. Américo Castro, Claudio Sánchez Albornoz, Agustín Viñuales, Emilio González-López, Rafael de Buen, José Ots, Niceto Alcalá-Zamora Castillo, Juan Peset, José Puche, Luis de Zulueta, Pedro Salinas, Blas Ramos, Enrique Rioja, Pedro Carrasco, Juan M. Aguilar, Manuel López-Rey et Antonio Flórez de Lemus.

29. Il fut révoqué post-mortem par la Commission Supérieure d'épuration, le 7 juillet 1941, en vertu de la loi du 10 février 1939 (Expediente académico y profesional de A. Machado y Ruiz, Madrid, Ministerio de Educación y Ciencia, 1975, p. 288).

30. J. A. Primo de Rivera, «Los intelectuales y la Dictadura», pról. a La Dictadura de Primo de Rivera juzgada en el extranjero, Madrid, 1931. 
qui exalta l'œuvre de D'Annunzio, de Malaparte ou de Marinetti. Par ailleurs, le régime franquiste s'efforça toujours de neutraliser plus que d'intégrer l'« ennemi intérieur ". La défaite de la République avait été celle des hommes de culture qui considérèrent, comme Unamuno ou Altamira, que leur peuple les avait trahis ${ }^{31}$. Nombre d'entre eux prirent le chemin de l'exil.

\section{De la « III ${ }^{e}$ République » À la troisième Espagne}

Cette fuite de cerveaux fut présentée comme une victoire par les partisans du manichéisme officiel. Les hommes les plus représentatifs de la culture espagnole rejoignirent ce que José Bergamín - l'un des intellectuels les plus engagés aux côtés de la République, malgré son catholicisme hétérodoxe qui intriguait - appellerait " l'Espagne itinérante " (la España peregrina). Les intellectuels libéraux s'éloignèrent de la révolution qui, à leur avis, avait éclaté dans la zone républicaine et ils ne voulurent pas vivre dans la zone " nationale ", privée de libertés publiques. Dans quelle mesure ont-ils contribué au naufrage du libéralisme et à l'effondrement de la République, comme le prétendit une historiographie récente qui les rend responsables des soubresauts historiques et même de la guerre civile, en les accusant d'avoir trahi leur cause soit en pratiquant le «rapt» de l'Espagne, soit d'avoir détruit délibérément le libéralisme en vigueur ? En devenant des intellectuels par leur intervention dans la vie publique, ces écrivains et professeurs auraient provoqué des phénomènes sociopolitiques qu'ils furent ensuite incapables de dominer. Ceux qui gouvernèrent n'auraient pas choisi la bonne méthode et auraient privilégié l'instruction et la culture (par déformation professionnelle) au détriment des réformes de structure, notamment la réforme agraire.

Il y eut aussi une troisième Espagne catholique dont l'erreur avait été de croire que l'on pouvait démocratiser une société hiérarchisée d'ancien régime en cours de massification. Ce groupe de démocrates chrétiens avait organisé des conférences sur le thème "contribuer à la connaissance mutuelle et aux relations entre les intellectuels catholiques d'autres pays et du nôtre $»^{32}$. Alfredo Mendizábal, un juriste d'Oviedo, secrétaire de la Unión Católica de Estudios Internacionales, constituée en juillet 1934 sous la présidence de Pedro Sangro y Ros de Olano ${ }^{33}$, avait fait partie de ce groupe inquiet face à l'anticléricalisme ambiant et s'était adressé, en mars 1933, à Manuel Azaña au nom de « la conscience juridique universelle. $»^{34}$.

31. R. Altamira, «Inventario de mis perdidas económicas, intelectuales y morales, por causa de la guerra civil de España», Rafael Altamira (1866-1951), Alicante, Instituto Juan Gil-Albert, 1987, op. cit., p. 225; P. Aubert, "Rafael Altamira, la redención nacional por la Historia», La Huella de Altamira, Madrid, Univ. Complutense, 2012, p. 37-90.

32. Juan Zaragüeta, «El grupo de la Democracia Cristiana, $A B C$, 18.IV.1934.

33. Apparaissent également les noms de Manuel Abril, Manuel de Falla, Alfonso García Valdecasas, Antonio Guarrigues, Juan Lladó et José Ma Semprún Gurrea, éditeur de la revue Cruz y Raya, créée en 1932 par J. Bergamín et Eugenio Ímaz.

34. $A B C, 29 . I I I .1933$, p. 10 et 12. Manifeste signé par Ramón Albó, Maximiliano Arboleya, 


\section{L'exil de l'été 1936}

Les critiques d'Unamuno et d'Ortega, puis le reniement d'Azorín, marquent le début d'une dissidence qui se confondra souvent avec une adhésion au régime du général Franco de la part de cette "Troisième Espagne " qui s'éloignait déjà de la République tout en proclamant son incompatibilité avec les deux camps. Entre le désir de préserver sa liberté afin de n'être pas accusés de servilisme envers le nouveau pouvoir et la nécessité de ne pas donner d'arguments aux ennemis de la République, tous les intellectuels ne voulurent pas choisir. Depuis le mois de juillet 1936, ceux qui disposaient de moyens financiers ou exerçaient un métier qui leur permettait de vivre à l'étranger, avaient pris le chemin de l'exil ${ }^{35}$. Moralement Unamuno se joignit à eux, après avoir approuvé brièvement le soulèvement, bien qu'il reconnût que son attitude, à l'intérieur du pays, était insoutenable $e^{36}$. Ces intellectuels avouent ne plus supporter l'intolérance des défenseurs de la République. Ils fuient la Révolution qui a éclaté dans la zone républicaine et ne veulent pas vivre dans la zone nationaliste privée de libertés. Quelques exemples illustrent leur malaise et révélent l'aporie de leur pensée. Madariaga, qui devint ensuite le modèle de l'intellectuel libéral exilé, affirma, en octobre 1936, à Londres, pour expliquer son silence face à la Guerre civile: " Je ne pouvais pas me déclarer en faveur des rebelles car ils représentaient une politique contraire à la mienne, ni en faveur des révolutionnaires, parce que je n'étais pas d'accord avec leurs méthodes, ni avec le but de certains d'entre eux. $»^{37}$. L'attitude d'Unamuno ne pouvait manquer de susciter des commentaires à cause de la sinuosité d'un chemin qui le conduisit à sa fameuse colère du 12 octobre $^{38}$. Face au déchaînement de la violence, l'écrivain affirmait avoir fait confiance aux militaires qui prétendaient sauver la République. En effet, aussi bien Queipo de Llano à Séville que Cabanellas à Saragosse terminaient leur manifeste par une référence à la République. De telle sorte que l'antimilitariste Unamuno crut candidement que ces militaires républicains allaient mettre de

Severino Aznar, Leopoldo Calvo Sotelo, José P. Gafo, Antonio de Luna, Alfredo Mendizábal, Salvador Minguijón, Manuel Siurot, Juan Zaragüeta et José Ma Zumalacarregui.

35. V. M. Rubio Cabeza, Los intelectuales españoles y el 18 de julio, Barcelona, 1975, p. 73-75; Hipólito Escolar, La cultura durante la Guerra Civil, Madrid, Alhambra, 1987, 408 p. Vicente Marrero Suárez, La guerra española y el trust de los cerebros, Madrid, 1961 ; María Zambrano, Los intelectuales en el drama de España. Ensayos y notas (1936-1939), Madrid, ed. Hispamerca, 1977, 208 p.; Fernando Díaz -Plaja, Si mi pluma valiera tu pistola. Los escritores españoles en la guerra civil, Barcelona, Plaza y Janés, 1979, 743 p. Aldo Garosci, Los intelectuales y la Guerra de España, Madrid, Júcar, 1981, 462 p. V. également, Nazario González, Historia de España, España actual. La Guerra civil (1936-1939), t.13.1, Madrid, Gredos,1989 ; Andrés Trapiello, Las armas $y$ las letras, Barcelona, Planeta, 1994, 429 p. Ces deux derniers livres sont des essais dépourvus de notes et de références.

36. M. de Unamuno, El resentimiento trágico de la vida, Madrid, Alianza, 1991, p. 43.

37. Genoveva García Queipo de Llano, «El fracaso de Madariaga. Intentos mediadores en la guerra civil espańola», Historia 16, n 116, p. 11-19.

38. José Miguel de Azaola, "El "alzamiento" de Unamuno en julio del 36», Estudios en homenaje a Ma Dolores Gómez Molleda, Salamanca, Narcea, vol. I, 1990, p. 191-211. 
l'ordre dans le pays en se fondant sur le rituel du pronunciamiento du siècle précédent. Le général Franco lui-même invoquait, le 18 juillet, «la Fraternité, la Liberté et l'Égalité» et Yagüe terminait sa harangue après la prise de Badajoz, le 14 de août, par cette invitation aux légionnaires : "Criez avec moi : Vive l'Espagne ! Vive la République ! Vive l'Armée ! ${ }^{39}$.

Cependant les événements ouvrirent les yeux de l'écrivain qui présidait alors la Commission d'Épuration. Crut-il que sa présence offrait un contrepoint libéral au mouvement militaire ? En tant que Recteur, il représentait le général Franco, chef de l'État de Burgos, dans les cérémonies officielles. C'est à ce titre qu'il ouvrit, à Salamanque, celle du 12 octobre 1936. Il entendit alors que le cri de la Légion que poussa Millán Astray, "Vive la mort!", ressemblait à celui des militaires qui menaçaient les intellectuels à la sortie de l'Athénée de Madrid : "Comme j’ai été naïf et léger en adhérant au mouvement de Franco, sans compter sur les autres et en faisant confiance - comme je le fais encore à ce prétendu caudillo. Car il ne parvient pas à civiliser ni à humaniser ses collaborateurs. [...] C'est-là une campagne contre le libéralisme et non contre le bolchévisme ", écrivait-il, en évoquant les persécutions dont faisait l'objet José $\mathrm{M}^{\mathrm{a}}$ Gil Robles après avoir avoué qu'il était prisonnier à Salamanque ${ }^{40}$. Unamuno dénonce le suicide moral de l'Espagne, car il ne voit aucune issue à cette situation qu'il interprète comme le fruit d'une dégradation de la vie politique. Mais l'esclandre du vieux professeur, abandonnant le camp nationaliste, ne signifiait pas qu'il allait revenir au bercail républicain. Il confiait, le 20 octobre, à l'écrivain grec, Nicos Kazantzakis, qu'il avait perdu tout espoir et partageait l'accablement de ses compatriotes. Il prit congé de lui en affirmant que l'intellectuel avait le devoir de cacher la vérité au peuple "pour que les hommes aient la force et le goût de vivre " - comme le faisait son héros Manuel Bueno - avant de conclure : "En ce moment critique que traverse l'Espagne, il était indispensable que je me misse du côté des militaires. Eux seuls mettront de l'ordre parce qu'ils ont le sens de la discipline et savent l'imposer. Ne faites pas attention à ce que l'on dit de moi. Je ne suis pas devenu un homme de droite, je n'ai pas trahi la liberté. Mais, le plus vite possible, il est urgent de rétablir l'ordre. Vous verrez comment, dans peu de temps, je serai le premier à reprendre la lutte pour la liberté. Je ne suis ni un fasciste ni un bolchévique. Je suis juste un solitaire! $»^{41}$. Deux jours plus tard, le 22 octobre, le général Franco destituait Unamuno de son poste de Recteur. El Socialista, du 3 novembre, annonça la nouvelle avec des accents caldéroniens: "On n’a plus besoin du traître ${ }^{42}$. Unamuno avait pris des notes intitulées El resentimiento

39. Manuel Aznar, Historia militar de la guerra de España, Madrid, Editora Nacional, 3e éd., 1958, t. 1, p. 179.

40. Lettres à Quintín de la Torre, 1.XII et 13.XII.1936, M. de Unamuno, Epistolario, t. II, op. cit., p. 350-352 et 354-355.

41. N. Kazantzakis, Du Mont Sinaï à lìle de Vénus. Carnets de voyage, trad. de Pierre Fridas et Giselle Prassinos, Paris, Plon, 1958, p. 154-155.Version espagnole, Obras selectas, Madrid, Planeta, 1979.

42. Allusion à la fin de La vie est un songe. "Del traidor no ha menester, cuando está la traición 
trágico de la vida, allusion ironique au livre qui l'avait fait connaître en Europe, en 1913, El sentimiento trágico de la vida. Il était convaincu que la guerre était un crime contre l'esprit et que l'antintellectualisme engendré par « la sauvagerie moscovite " et "la stupidité catholico-traditionnaliste " s’était généralisé ${ }^{43}$. L'écrivain notait dans ce dernier brouillon qu'il devait reconsidérer son œuvre et "comprendre et repenser l'Espagne ". Azaña évoqua dans ses mémoires la fuite des intellectuels qui profitèrent de missions culturelles ou diplomatiques ou d'une tournée de conférences dans les universités étrangères ${ }^{44}$. Ces sorties suscitèrent la méfiance des militants républicains.

La figure de l'intellectuel qui exploitait sa réputation comme un capital moral, réclamait un poste important ou une sinécure puis faisait le mort à la première averse, choquait Manuel Azaña. "Des républicains bons pour être ministres et ambassadeurs en temps de paix. Des républicains prêts à émigrer en temps de guerre ", notait-il encore en 1939 dans son journal. Cet épisode confirmait son préjugé hostile à l'endroit des gens de sa corporation ; il se plaisait alors à se présenter comme un bouc émissaire : "Je me reconnais étranger à cette époque. Les hommes comme moi, nous sommes arrivés trop tôt ou trop tard. À moins que notre inutilité n'appartienne à tous les temps, à toutes les situations. Tout ce qu'il faudra faire désormais en Espagne, foule aux pieds mes convictions, contredit mes inclinaisons, mes goûts " $"$. Le peuple en armes - en qui Azaña croyait avoir vu jadis la nation - commettait aussi des crimes. La déception d'Azańa ne fut pas moindre que celle de ses compagnons réfugiés dans cette troisième Espagne qui ne fut qu'une transition vers l'ordre franquiste. Pérez de Ayala les avaient mis en garde en 1927, en constatant que ces intellectuels prenaient trop au sérieux leur rôle d'opposants au régime : "Nous vivons à une époque de transition et d'incertitude. Dans aucun coin de la terre nous ne trouverons une unité idéologique et sentimentale. " ${ }^{46}$. Il posait ainsi prophétiquement la question de l'identité, de la situation et du rôle de l'intellectuel dans la crise de la société bourgeoise.

\section{Militantisme républicain, diplomatie et néolibéralisme}

En 1936, Antonio Machado, jadis autodéfini poète intimiste, se présenta comme un milicien ${ }^{47}$ et se passionna pour la politique, au point de devenir

pasada " ( On n’a plus besoin du traitre lorsque la trahison est consommée. »).

43. M. de Unamuno, El resentimiento trágico de la vida. Notas sobre la revolución y guerra civil españolas, Madrid, Alianza, 1991, p. 31. et 47.

44. P. Aubert, "Manuel Azaña : un intellectuel au Pouvoir», article cité.

45. M. Azaña, Memorias políticas y de guerra. 1937-39, Madrid, Aguado, 1981, t. 1, p. 83, 26.VIII.1937, p. 359; 2 .XII.1939, Ibid., p. 617. La velada de Benicarló, Ibid., p. 435.

46. «Público, pueblo y plebe », El Sol, 24.XI.1927.

47. El Sol, 1.X.1920; «Palabras del insigne poeta Antonio Machado», Boletín periódico de la Revolución (Consejo Regional de Defensa de Aragón), Fragua, n 11, 4.XII.1936. Ce texte a été publié par Robert Marrast (Puerto, Universidad de Puerto Rico, n 1, XII.1967, p. 74-77; puis PC, t. II, p. 2171, mais daté du 29.XI.1936 et sans mention de sa source journalistique. Les 
un agitateur lorsque les grands intellectuels se retiraient de la scène publique. Il avait cédé aux sollicitations de Bergamín et assumait la présidence du $\mathrm{II}^{\mathrm{e}}$ Congrès des Écrivains Antifascistes de Valence en 1937. Persuadé qu'il lui fallait prendre part à l'épopée populaire, mettre son lyrisme au service de cette III ${ }^{e}$ République issue des urnes qui donnèrent la victoire au Front Populaire - «Elle est sans doute quelque peu frivole la position du philosophe lorsqu'il pense que la guerre est une impertinence qui vient perturber par surprise le rythme de ses méditations "-, Machado ne cacha pas l'admiration que lui inspiraient ces intellectuels qui assumèrent dignement les tâches du gouvernement ${ }^{48}$. Il expliqua sa radicalisation par un réflexe patriotique ${ }^{49}$, bien que l'on sentît dans ses derniers poèmes une aspiration à la tranquillité, le poète prêta sa plume à la propagande républicaine ${ }^{50}$. Fut-il candide au point de se laisser manipuler ? Le témoignage de León Felipe, qui raconte comment ils récitèrent des poèmes, le 4 juillet 1937, sans micro, devant un auditoire de cinq cents personnes sur la place de Castelar à Valence, en dit long sur la nature des épreuves qu'ils endurèrent parfois. Debout sur l'estrade alors qu'il était perclus par l'artériosclérose, Machado se vit refuser une chaise et essuya l'insolence du ministre de l'Instruction publique, Jesús Hernández ${ }^{51}$. Le poète insiste cependant sur le comportement exemplaire de l'intellectuel qui doit être la conscience de son peuple ${ }^{52}$.

D'autres crurent qu'ils pouvaient être utiles depuis l'exil. Les socialistes De los Ríos, Araquistáin et Jiménez de Asúa s'efforcèrent d'obtenir sinon une intervention du Gouvernement français, tout au moins le respect des contrats sur les ventes d'armes ${ }^{53}$. Après son voyage à Valence, au cours duquel il était venu voir Azaña, Sánchez Albornoz s’interroge sur l'opportunité d'une initiative des intellectuels en faveur de la paix ${ }^{54}$. L'historien, qui est convaincu

notes des pages 2521-2522 n'apportent aucun éclaircissemnt. Nous maintenons le titre et la date mentionnés par R. Marrast.

48. $P C$, t. II, p. 1918 ; p. 2394 ; p. 2428.

49. P. Aubert, «Gotas de sangre jacobina», P. Aubert (éd.), Machado hoy-1939-1989, Madrid, Casa de Velázquez, 1994, p. 309-362. A. Machado, "Glosario de los trece fines de guerra», La Vanguardia, Barcelona, 13.XI.1938. Robert Marrast-Ramón Martínez-López (eds.), Prosas y poesias olvidadas, París, Centre de Recherches de l'Institut d'Études Hispaniques, 1964, p. 130; PC, t. II, p. 2284-2288.

50. Aux hebdomadaires Ahora, Ayuda, de la section espagnole du Secours Rouge International, en 1936, aux revues de la Maison de la Culture de Valence, en 1937, à Hora de España, et Madrid en 1937, Madrid puis au Suplemento literario del Servicio Español de Información, à Nuestro Ejército, en 1938, Fragua etc.

51. L. Felipe, La insignia, México, Biblioteca León Felipe,1939, p. 58-60.

52. Obras, Buenos Aires, Losada, 1964, p. 576.

53. M. Tuñón de Lara, "Todavía la no-intervención (julio-agosto 1936)», Historia contemporánea, $\mathrm{n}^{\circ}$ 5, 1991, p. 171-186. Les historiens anglo-saxons, alimentèrent un débat à propos des origines de la Guerre civile: montée de la conflictivité, climax, rejet ; Américo Castro et Sánchez Albornoz y prirent part. La question était de savoir si celle-ci avait commencé avec le roi wisigoth Wamba ou avant etc.

54. Sánchez Albornoz au Dr. Marañón, Fundación Ortega-Marañón, lettre citée par Gómez Santos, op. cit., p. 51. 
que "le triomphe de l'un ou l'autre camp serait la barbarie dans notre patrie pour de nombreuses années ", s'efforce de susciter une médiation argentine $e^{55}$ qui échoua au moment de la non-intervention de la Grande-Bretagne et de la France. Le 19 juin 1937, Madariaga publie simultanément dans The Times de Londres, Le Temps, de París et La Nación de Buenos Aires, un article au ton désespéréé : "L'Espagne ne pourra se sentir solidaire d'une victoire qui - quel que soit le vainqueur - sera étrangère. De telle sorte que, quel que soit le vainqueur, c'est toujours l'Espagne qui perdra ". Il s'éloigna ensuite de la réalité espagnole en professant depuis l'exil un antifranquisme radical. Il tenta en vain de s'interposer entre les deux camps sans obtenir l'appui des puissances européennes, en réclamant diverses actions des gouvernements britannique et français, et notamment afin de faire en sorte que la politique de non-intervention soit une réalitée ${ }^{57}$ En novembre 1944, Madariaga publia sa fameuse lettre ouverte au général Franco dans laquelle il le priait de quitter le Pouvoir: "Mon général, partez ... Je ne le dis pas pour vous offenser, mais le Chef d'un camp de la Guerre civile, ne peut être utile au moment de faire l'unité espagnole. $"^{58}$.

Désorientés, se sentant trahis par la République, dont ils se crurent les pères, certains intellectuels, moins engagés socialement, virent dans le néolibéralisme l'avènement d'un monde plus serein, même si tous n'étaient pas convaincus que les marchés étaient auto-correcteurs. Ils ne renoncèrent pas au socialisme libéral, mais cherchèrent une voie moins agressive que le laissezfaire manchestérien, dans les idées d'économistes hostiles à Keynes, tels que von Mises, Röpke, ou Hayek. Castillejo, qui avait revendiqué le libéralisme, dans une série d'articles publiés dans le quotidien El Sol, au printemps 1936 ${ }^{59}$, intervint, ainsi que Madariaga, au Colloque Walter Lippmann à Paris du 26 au 30 août 1938. Ils se sentirent confortés par la présence de Jacques Rueff, qui se prétendait " libéral de gauche », sinon par celle de Raymond Aron, ou de Gaëtan Pirou qui expliquait cependant en 1939 qu'il ne fallait pas que la liberté économique menaçât les autres formes de liberté ${ }^{60}$.

Entre 1936 et 1939, rien ne permet de connaître l'itinéraire idéologique d'Azorín sinon qu'il avait oublié qu'il était l'auteur de l'expression « République des intellectuels ». Car, après avoir été succesivement anarchisant, républicain fédéral, partisan de Maura, de La Cierva, du général Primo de Rivera et à nouveau républicain, il était devenu franquiste. Les cinquante articles qu'il publia dans $A B C$ et Arriba, l'organe de la Phalange, entre le 30 novembre 1939 et le premier octobre 1946 - le premier s'intitule «Elegía a José Antonio » et

55. Ibid, op. cit., p. 41. Lettre au Dr. Marañón non datée (1938), citée, p. 51.

56. S. de Madariaga, España, 11 é. éd., Madrid, Espasa-Calpe, 1978, p. 606.

57. Genoveva García Queipo de Llano, «El fracaso de Madariaga. Intentos mediadores en la guerra civil espańola», Historia 16, n 116, p. 11-19.

58. S. de Madariaga «General, go", Spectator, 8.XII.1944, vol. 173, p. 523.

59. J. Castillejo, «La campaña electoral. El nuevo liberalismo», El Sol, 9.II.1936; et la série intitulée: "Los problemas de la Republica.», El Sol, 5, 23, 29. III; 5-19.IV; 5.XII.1936.

60. Gaëtan Pirou, Néo-libéralisme, néo-corporatisme, néo-socialisme, Paris, Gallimard, 1939. 
l'avant-dernier, "José Antonio en la historia »-, prouvent qu'il fut un panégériste du franquisme ${ }^{61}$, au point d'élever Franco au rang de "maître des écrivains nationaux ». Un tel zèle était destiné à faire lever l'interdiction professionnelle dont il avait fait l'objet en 1940. Comme toujours, sauf au temps de l'idéalisme de sa jeunesse, il est du côté du Pouvoir. Son départ ne s'explique pas pour des raisons politiques. Il fut choqué par l'exécution de deux de ses amis : celle de son beau-frère d'abord, Manuel Ciges Aparicio, Gouverneur civil d'Ávila, fusillé le 19 juillet 1936 par les franquistes ; celle de Ramiro de Maeztu ensuite, qu'un groupe de miliciens sortit de prison pour l'exécuter, le 28 octobre 1936, dans le cimetière d'Aravaca. Il avait donc des raisons pour craindre les réactions des partisans des deux camps à un moment où circulaient les plus folles rumeurs, notamment celle qui prétendait qu'Unamuno avait été fusillé6 ${ }^{6}$. Dès qu'il reçut sa nouvelle carte de presse, l'écrivain collabora au quotidien phalangiste Arriba et publia, en mars 1941, deux volumes de mémoires dédiés aux deux censeurs Antonio Tovar et Maximiano García Venero. Il préféra se soumettre au régime afin de poursuivre en Espagne une œuvre litéraire qui ressemblait désormais à une activité de propagande. Dans une lettre qu'il lui adressa depuis Paris, le 21 janvier 1939, Azorín sollicita la clémence du Caudillo et l'autorisation pour les intellectuels républicains de revenir en Espagne ${ }^{63}$. Azorín sera ensuite l'un des auteurs les plus célébrés par le franquisme, après avoir été le héros de ce chant du cygne de l'intellectuel libéral. Ces exigences allaient à l'encontre de l'esprit de la Croisade auquel se référaient les dignitaires du régime. De telle sorte que ceux qui étaient partis restèrent hors d'Espagne - «je suis parti pour rester en vie», dira Francisco Ayala - et ceux qui étaient restés soignaient leur anxiété en se réfugiant dans une érudition de bon aloi. Cette version franquiste de la pureté de sang allait jusqu'à contester le comportement et la couleur idéologique des individus. Marañón livra ses réflexions sur l'émigration politique depuis Garcilaso dans son essai Españoles fuera de España. Pérez de Ayala reprit sa lecture des auteurs latins et redonna à $A B C$, en les mettant au goût du jour, des articles publiés jadis dans la presse de Buenos Aires. Un témoignage suggère qu'Ortega, qui ne faisait plus allusion à la vie politique qu’à travers le prisme de l'Histoire, finit par se rapprocher du régime franquiste ${ }^{64}$. Il reviendra cependant sur le rôle de l'intellectuel en 1944, en développant les mêmes arguments qu'en 1923 pour justifier son retrait de la politique : «les

61. P. Aubert, "Azorín et la politique: les méandres du "libéralisme instinctif "”, Bulletin d'Histoire contemporaine de l'Espagne, $\mathrm{n}^{\circ} 44$, Las derechas en España, Aix-en-Pce, PUP-UMR Telemme-CNRS 6570, 2010, p. 179-229; E. Inman Fox, «Azorín y el franquismo. Un escritor entre el silencio y la propaganda", Anales Azorinianos, no 4, Murcie, Fundación Cultural CAM, 1993, p. 81-117.

62. J. Bergamín, ABC, 29.IX. 1936, p. 13.

63. Ramón Serrano Suñer, Entre el silencio y la propaganda. La Historia como fue. Memorias, Barcelone, Planeta, 1977, p. 410.

64. Juan Demetrio Ramos, attaché de pressse à l'Ambassade d'Espagne à Buenos Aires, à J. A. Giménez Arnau, 31 juillet 1940, Archives Générales de l'Administration, Alcalá de Henares, Vice secretaría. Educación popular, Archivo general, 1938-1941. B. 49, caja núm. 245. Ce document nous a été aimablement communiqué par Manuel L. Abellán. 
intellectuels, qui étaient tout, ont fini par n'être plus rien " ${ }^{65}$. Il lui semblait que l'intellectuel était victime de l'éclipse de la raison qui affectait le monde occidental.

\section{CONCLUSION : DE LA FRUSTRATION À LA DISPARITION}

Lorsque leur action était confondue avec celle du gouvernement républicain, les intellectuels entreprirent des réformes structurelles que la droite annula à partir de 1933. La rupture de l'ordre constitutionnel était le fruit de la politique d'obstruction menée par la droite légaliste après sa victoire électorale de novembre 1933 et du virage des socialistes qui représentaient une force électorale plus importante que leurs alliés républicains et avaient un poids supérieur aux partis révolutionaires. La République a-t-elle été victime de cette radicalisation du PSOE, dès lors que les dirigeants de celui-ci se proclamaient marxistes, tandis que la CEDA envisageait l'instauration d'un État corporatif ? Après avoir prétendu écrire l'Histoire face à des événements qui leur échappaient, ces intellectuels se sentirent inutiles. Entre le peuple libéral inexistant -il s'était massifié et ne voulait plus entrer au parlement car il était dans la rue - et la nation inachevée, l'intellectuel courait le risque d'être manipulé par le Pouvoir ou de passer pour un irresponsable. «Encore une fois il va falloir couper le blé en herbes ", répétait Azaña ${ }^{66}$, ou "les gauches seront chassées du Pouvoir sans avoir pu gouverner ». Mais la frustration de l'intellectuel venait aussi du fait que le débat social faisait défaut. Dans un monde où la "Croisade " entreprise par l'extrême droite convertissait l'idée en dogme et les exécutions devenaient un spectacle public ${ }^{67}$, la démocratie restait une utopie et l'intellectuel, s'il n'était pas un militant, était inutile. La prière du jeune León Felipe à ses aînés en dit long sur sa désillusion - " ne me racontez plus d'histoires " - autant que la rage du philosophe Ortega y Gasset qui constate : "l'intellectuel n'existe plus socialement, c'est un paria et un malfaiteur ${ }^{68}$. Après la tragédie, dans la société de l'Après-guerre, les triomphateurs furent vindicatifs et accusèrent les intellectuels de tous les maux. Ortega, qui exaltait fièrement en 1927 le rôle prépondérant de l'intellectuel, théorisait à nouveau en 1940 sa propre situation : désormais l'intellectuel n'était plus rien. C'est ainsi qu'en quelques mois, l'intellectuel espagnol passa de l'illusion à la frustration et de celle-ci - lorsqu'il avait survécu - à la nostalgie. Car on continua en Europe à exalter sa figure puisque son histoire était celle de la lutte pour la liberté, qui, comme toutes les métaphores, a le lyrisme de l'absolu.

65. J. Ortega y Gasset, «La razón histórica», conférence de Lisbonne, 1944, O.C., t. 12, p. 241 et 248; "El intelectual y el otro", La Nación, Buenos Aires, XII 1940, O.C., t. 5, p. 508 ; «Apuntes sobre el pensamiento, su teurgía y su demiurgía. Crisis del intelectual y crisis de la inteligencia", Logos, Facultad de Letras, Univ. Buenos Aires, XII 1941, O.C., t. 5, p. 517-547.

66. M. Azaña, Obras Completas, México, Oasis, 1966, t. III, p. 626.

67. Rafael Abellá, La vida cotidiana durante la Guerra civil, Barcelone, Planeta, 1978, p. $62-68$.

68. J. Ortega y Gasset, «El intelectual y el otro», art. cité. 